\title{
Oral and Written Academic Discourse: Models of Investigation
}

\author{
Seda Gasparyan, Astghik Chubaryan, Ruzanna Karapetyan
}

Yerevan State University

\begin{abstract}
$\mathrm{T}$ he increase of cross-cultural contacts in the scientific community and the consequent globalization of the scientific knowledge have led to the clash of various cultures and languages in the academic environment displayed mainly on the linguistic plane. The English language has come to serve as a lingua franca, a medium for disseminating the results of the scientific research conducted throughout the globe, exchanging opinions, supporting or rejecting hypotheses. Hence, it can be inferred that to a certain extent domainspecific English is an absorber of the cultural and linguistic peculiarities of scholars of different nationalities to be revealed and studied for promoting the further communication progress in the given area. In the following an attempt is made to tackle certain issues and to propose some promising models for the investigation of various phenomena with regard to the field mentioned. The research is conducted in two directions: written and oral intercultural academic discourse. It is to be stipulated that in the field of written discourse a thorough investigation of a specific linguistic unit, namely the absolute constructions, has been made with the subsequent presentation of the appropriate statistic results and the qualitative, theoretical generalization, whereas for the oral discourse we only aimed at elaborating a model and stating the overall objectives for further investigations.
\end{abstract}

\section{The Role of Absolute Constructions in Multicultural Written Academic Discourse}

Written academic discourse is a very broad notion and requires consideration of various aspects both on the linguistic and extra-linguistic planes. For this purpose in the given work such a linguistic unit as an absolute construction is viewed under the light of functional linguistics. Hence, the main proposition underlying the research is that all the language units in the text are organized and functionally bound to the meaning they express. In other words, the role and the peculiarities of the usage of absolute constructions are investigated in the texts of specialized discourse in terms of their functionalism.

Firstly, the qualitative-quantitative analysis of absolute constructions in Natural and Social Sciences is conducted. To be more specific, the classification of the functions performed and the corresponding statistics is presented. A comparison is drawn between the functioning of the linguistic unit in question in Social and Natural Sciences. Secondly, the distribution of certain functions and their statistics in the texts written both by native and non-native speakers is provided. Thus, it may be claimed that this approach to the analysis is culturally-oriented; but on the other hand it is examined within the framework of universal principles of academic discourse. And eventually, certain theoretical assumptions on the basis of functional linguistics principles are made to base and explain the statistical data obtained. 
Before getting down to the immediate analysis it is worth dwelling upon the sources of the authentic material which served as an empirical basis of the investigation. For the first part of the analysis 153 pages of on-line research papers from the field of Sociology and 114 pages of highly specialized papers in Physics and Biology from the academic online data-base have been examined. All the texts are written by English-speaking scholars which we find mostly reasonable for the aims pursued in this part of the investigation. The second part of the analysis involves examination of the texts from Natural Sciences only, again taken from the academic online data-base. This choice is justified by the fact that is a pre-print edition and the papers here are not subject to proofreading by English-speaking specialists. Thus from the cultural viewpoint these papers are likely to provide precise results to the highest degree.

It should be stressed once more that the emphasis in this work is placed on the general theory of language functions and their realization in speech, so we will proceed beyond the purely linguistic, morpho-syntactic characteristics of the construction investigated, instead suggesting a more global, encompassing insight into the use of this construction in academic discourse.

A thorough analysis of the authentic material in terms of the semantic and logical roles that the grammatical category in question acquires in Academic English revealed the following functions: specification, condition, explanation, reason, description-specification, description-explanation, specification-explanation, consequence, specificationaddition. Presented below are the results of the quantitative analysis displaying the use frequency of each of the semantic roles fulfilled by the linguistic unit analyzed along the disciplines.

\section{The Functions of AC in Natural and Social Sciences}

\begin{tabular}{|c|c|c|}
\cline { 1 - 2 } Fields & \multirow{2}{*}{ Natural Sciences (114p.) } & Social Sciences (153p.) \\
\cline { 1 - 1 } Functions & 10 & 3 \\
\hline Specification & 2 & 0 \\
\hline Condition & 3 & 0 \\
\hline Explanation & 1 & 1 \\
\hline Reason & 1 & 0 \\
\hline Description-specification & 1 & 0 \\
\hline Description-explanation & 18 & 4 \\
\hline Total & & \\
\hline
\end{tabular}

As is seen from the table, the number of absolute constructions in Natural Sciences prevails almost twice. Which might be the reasons accounting for this distribution? It is well-known that the sentences augmented by absolute constructions are considered to be semi-complex because of the omission of certain conjunctions and the use of non-finite 
verbs which are devoid of the capability to express such categories as tense, mood, aspect, number and person. On the one hand, this compresses the linguistic volume of the information transferred permitting more economical and concise communication of information, which, to a significant extent, is a must for contemporary science; but on the other hand, this requires both from the speaker/writer and the listener/reader strong abilities for the pragmatic inference of the covert information. So it is the background knowledge and more analytical bias of scientific research that come to play the key role for the adequate comprehension of information. It is an obvious fact that the domain of Natural sciences presupposes more rigid background knowledge of the subject, more familiarity with some laws and regularities for understanding the argument development, and prefers information transmission in an economical and concise way, whereas the discourse in Social sciences is more extended, lengthy, allowing extensive descriptions and explanations; and as a consequence, the role of absolute constructions diminishes in this domain. This may be, though not the only, but one of the strongest arguments in favour of the distribution of absolute constructions along the disciplines presented in the table above.

The table provided below presents the results of the multicultural analysis of the absolute construction use both by native speakers, and by Armenian, Russian and Italian scholars writing in English as a lingua franca in contemporary academic community.

The Functions of AC in English as a Lingua Franca

(The analysis refers to the field of Natural Sciences only)

\begin{tabular}{|c|c|c|c|c|c|c|c|c|c|c|}
\hline Functions & \multirow{2}{*}{ Spec. } & \multirow{2}{*}{ cond. } & \multirow{2}{*}{ expl. } & \multirow{2}{*}{ reason } & \multirow{2}{*}{$\begin{array}{l}\text { descr.- } \\
\text { spec. }\end{array}$} & \multirow{2}{*}{$\begin{array}{l}\text { descr.- } \\
\text { expl. }\end{array}$} & \multirow{2}{*}{$\begin{array}{l}\text { spec.- } \\
\text { expl. }\end{array}$} & \multirow{2}{*}{ conseq. } & \multirow{2}{*}{$\begin{array}{l}\text { spec.- } \\
\text { addit. }\end{array}$} & \multirow{2}{*}{ total } \\
\hline Languages & & & & & & & & & & \\
\hline $\begin{array}{c}\text { English } \\
\text { scholars }(114 \mathrm{p})\end{array}$ & 10 & 2 & 3 & 1 & 1 & 1 & 0 & 0 & 0 & 18 \\
\hline $\begin{array}{c}\text { Italian scholars } \\
(117 p)\end{array}$ & 20 & 1 & 0 & 2 & 0 & 0 & 0 & 1 & 0 & 24 \\
\hline $\begin{array}{c}\text { Russian } \\
\text { scholars(118p) }\end{array}$ & 9 & 2 & 1 & 0 & 1 & 0 & 0 & 0 & 1 & 14 \\
\hline $\begin{array}{c}\text { Armenian } \\
\text { scholars }(112 p)\end{array}$ & 16 & 0 & 0 & 0 & 2 & 0 & 1 & 0 & 0 & 19 \\
\hline
\end{tabular}

The data above manifests that the absolute construction, specific of the English language only, is almost equally used by scholars of different nationalities. The grammatical unit under discussion expresses such notions as specification, condition, explanation, cause, effect and so on which are endowed by high degree of informativeness and are thus essential for the language of science universally. And consequently this universality of certain extra-linguistic realia, in the given case in the academic community, is expressed on the linguistic level by frequent use of the construction atypical for their 
native languages by non-English speakers. This fact can be accounted for by the phenomenon of "hybridisation" of English in the academic environment in different countries.

\section{Pragmatic Insight into the Polite/Impolite Communication in Academic Discourse}

Below we propose certain reflections on the scientific directions and theoretical models which could prove quite fruitful for the analysis of oral intercultural academic discourse. On a broad scale the oral intercultural academic discourse is suggested to be viewed in the light of face and impoliteness theory and the role of power for exercising impoliteness in this or that situation (Bousfield 2008) with particular accent on the role of impoliteness, the cases of intentional or/and casual uses of impoliteness - both as an elaborated strategy and an accidence - for achieving certain perlocutionary effects, especially nowadays that conflictology and misunderstanding have tremendous impact on people's communication which is to a great extent accounted for by impolite speech acts. Indeed, as is pointed out by D. Bousfield "We must recognize that there are discourses in which conflictive illocutions (just one set of which is impoliteness) are not marginal human phenomena" (Bousfield 2008:1). Transfer to the field of academic communication makes it evident that such manifestations of academic discourse as dissertation defense, introduction of new ideas, exams at universities, seminars, round table discussions, etc. can be characterized as highly conflictive situations with the ensuing conflictive illocutions and face-threatening speech acts (FTA) and comprise the lion's share in the communication at various academic levels and strata. It is to be stipulated here that we proceed from the notion of face as the public that every adult tries to project, and the subsequent classification of the negative and positive faces, where the negative face is defined as a desire of the speaker to be unimpeded in actions, to feel free, not to be imposed upon; and the positive face as a speaker's desire to be approved of, give and receive respect (Brown and Levinson 1987).

Various scholars have elaborated and classified politeness/impoliteness strategies meant to resist the face-threatening acts with regard to the positive or negative wants of the speaker and the hearer. Here the variables of power and social ranking mainly predetermine the choice of corresponding strategies and the appropriate linguistic means to fulfill specific aims. In the sphere of academic discourse the role of power and social distance acquires a more substantial weight, for the subordination principles in this domain are observed more strictly and consistently between students and professors, junior and senior researchers, scholars and principal investigators, etc. So quite often impoliteness strategies are veiled and thinly disguised under the mask of politeness depending on the symmetric and asymmetric social relations with the situation being more complicated due to the national-cultural diversity of the communicants. In the academic discourse this can be manifested in such common situations as, for example, introducing a completely new notion which might contradict the unanimously accepted facts, defending different theses, trying to indicate certain misconceptions in the opponent's judgments during discussions, in book or article reviews, etc. In the long run all the strategies employed to achieve the ultimate goals in the above mentioned stances could be defined as face- 
threatening acts, as they are directed to aggravate the negative or positive wants of the hearer. However the strategies chosen differ drastically according to degree of power and the interrelation between the speakers. As is stated by J. Culpeper "The momentum for this section derives from an off-the-cuff comment made to me by Miriam Locher: "Isn't all impoliteness a matter of power?" (Bousfield 2008:17).

Taking into consideration the above-mentioned factors, research aiming at elucidating the nature of the power and politeness/impoliteness interrelation within the academic environment with a special emphasis on the cultural factor, is proposed to be conducted. Recordings of academic conversations in different settings and answers to the questionnaire might serve as an empirical material for the research. In what follows definite corner questions worth attention and analysis are presented:

\section{POWER_POLITENESS \\ POWER-IMPOLITENESS}

All the questions refer to the communication in the academic environment and the interrelation between the communicants of an academic discourse

- What does impoliteness have to do with power?

- Can inferiors exercise power over superiors?

- Can the communicative strategy employed by people with inferior status for achieving certain goals, namely constraining the hearer's action-environment, be characterized as impolite?

- If no, what is it? If yes, can it be further described as disguised impoliteness, diplomatic impoliteness, strategic impoliteness, or even over-politeness?

- What is the role of purely linguistic means for the realization of the "disguised impoliteness, diplomatic impoliteness, strategic impoliteness" strategies?

- What national and cultural factors predetermine the choice of strategy and the linguistic means for fulfilling the strategies mentioned?

The other two conceptual frameworks, the analysis could rely on, are the strategic communication theory (Kashkin 2000) and the theory of speech influence (Kotov, Vlasyan 2007). According to the former theory any kind of communication involves communicative goals, participants of the communication and the strategy elaborated by the participants, and aimed at the final results or goals of the speech act. The second theory states that any communication presupposes influence or action-environment constraining of the hearer realized both by linguistic and factual behavior of the speaker. Naturally the hearer - consciously or subconsciously resists this influence trying to guard his/her interests, or as is stated by Culpeper tries to avoid "face loss" (Bousfield 2008:36).

On the basis of these theories we propose the following model for the investigation of the power and politeness/impoliteness interrelation in the academic environment considering the role of the cultural factor. 


\section{POWER AND THE POLITENESS/IMPOLITENESS STRATEGIES SPEECH INFLUENCE IN ACADEMIC SETTING}

POWER

(participants with superior rank)

Communicative strategy: Impoliteness

Language

(syntax, lexis, style) to be filled in to be filled in after the analysis
NO POWER

(participants with inferior rank)

Persuasion

Disguised impoliteness

Suggestion

Diplomatic impoliteness

Strategic impoliteness

However, this model strongly depends on a series of factors such as:

a. discourse situation;

b. different participant perspectives;

c. negotiation in discourse;

d. dynamism of the discourse;

e. cultural factors.

Hence, as a result of the empirical material analysis the research model proposed in the present paper seeks: 1) to follow the stability or the degree of displacement of the units in the model due to the factors mentioned above and 2) to classify the linguistic units - syntactic, lexical, stylistic - for fulfilling the specific strategy in view of all the other factors mentioned.

\section{References:}

1. Bousfield, D. (2008) Impoliteness in Interaction. Amsterdam: John Benjamins Publishing Company.

2. Brown, P. and Levinson, S. (1987) Politeness: Some Universals in Language Usage. Cambridge: Cambridge University Press.

3. Gotti, M. (2008) CADIS - A Corpus of Academic Discourse. // Investigating English with Corpora. / Ed. by A.Martelli and V.Pulcini. Polimetrica.

4. Halliday, M.A.K. (1985) An Introduction to Functional Grammar. London: Edward Arnold.

5. Impoliteness in Language. Studies on its Interplay with Power in Theory and Practice. (2008) Ed. by D.Bousfield and M.A. Locher. The Hague: Walter de Gruyter.

6. Kashkin, V.B. (2000) Introduction to the Theory of Communication. Voronezh: Vilnius Gediminas Technical University.

7. Vlasyan G. (2007) Priroda rechevogo vozdeistviya. // Vestnik Chelyabinskogo gosudarstvennogo universiteta, N 20 (98). 
8. Kotov, A. Opisanie rechevogo vozdeistviya $v$ lingvisticheskoy modeli. $<$ http://www.harpia.ru/theory.html $>$

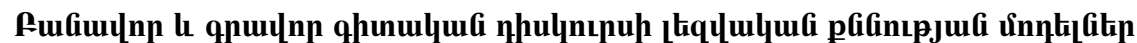

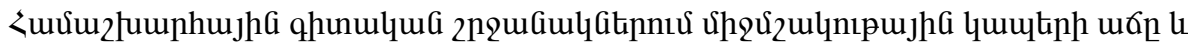

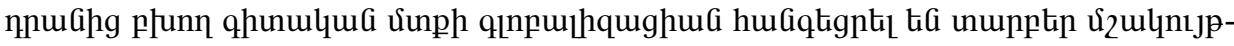

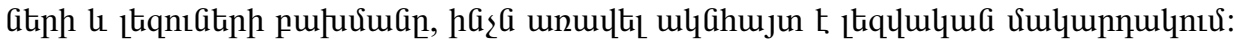

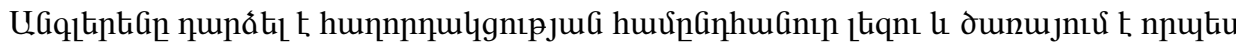

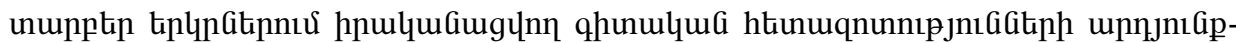

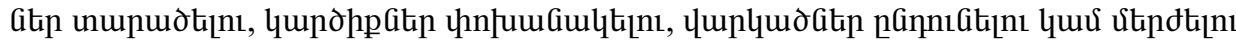

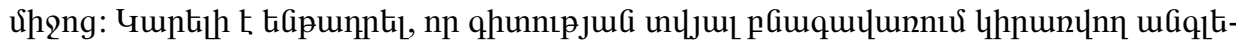

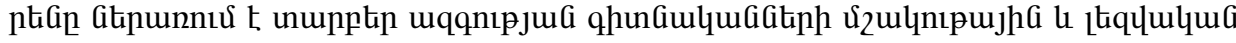

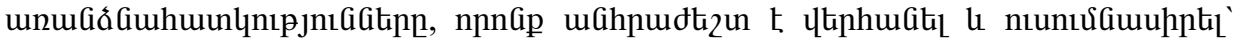

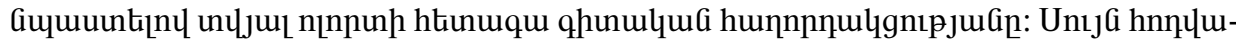

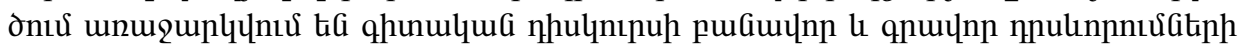
htinuqnunnıpjua tiplnn unnthl: 